\title{
Optimized method for rapid protein electroblotting
}

\begin{abstract}
Protein electroblotting is a common method for transferring proteins out of a polyacrylamide gel onto a membrane for subsequent western blotting. With a high-current power supply, such as that found in the Thermo Scientific ${ }^{\mathrm{TM}}$ Pierce ${ }^{\mathrm{TM}} \mathrm{G} 2$ Fast Blotter, and a high-ionic strength transfer buffer, protein transfer from nitrocellulose or polyvinylidene difluoride (PVDF) membranes can be achieved in 5-10 m, even with proteins as large as $300 \mathrm{kDa}$.
\end{abstract}

\section{Introduction}

Western blotting is a commonly used technique for detection of proteins. The quality of data derived from western blotting is dependent on several factors, including the sample integrity, blocking buffer, antibody quality, antibody concentration, type of membrane and assay technique. One of the most critical factors for satisfactory western blot results is consistent and efficient transfer of the proteins from the gel to the membrane. Traditional transfer techniques include tank and semidry transfers. The Pierce ${ }^{\mathrm{TM}}$ G2 Fast Blotter (Fig. 1) represents a semidry transfer method.

Tank transfer is often considered the optimal method for electroblotting because it is very reproducible and generally provides good transfer efficiency. In tank transfer, the transfer sandwich is secured in a cassette and submerged in a tank of transfer buffer. This method uses a large volume of buffer containing methanol and is usually performed with an ice pack within the transfer tank or by placing the whole apparatus in a cold room to offset the heat that is generated. Tank transfer takes a minimum of $2 \mathrm{~h}$ and longer for larger proteins. With semidry transfer, the gel and membrane are sandwiched between two pieces of filter paper that have been saturated in transfer buffer. This method has become quite popular because it uses less buffer and generally requires less time (only 30-60 m). The efficiency of semidry transfer is generally perceived as inferior to tank methods, especially with respect to the transfer of high-molecular weight proteins.

Rapid protein electroblotting, a more recent technique, uses a high-ionic strength transfer buffer in combination with a high-current power supply that greatly increases the rate of protein migration from gel to membrane. By increasing the current 10 -fold or more across the surface of the sandwich, transfer efficiency equivalent to tank and semidry methods can be attained in as little as 5-10 m.

Greg Kilmer, Brian Webb, Boguslawa R Dworecki, Eric Hommema, Steve Shiflett \& Priya Rangaraj

Thermo Fisher Scientific, Rockford, Illinois, USA. Correspondence should be addressed to P.R. (priya.rangaraj@thermofisher.com) or B.W. (brian.webb@thermofisher.com).

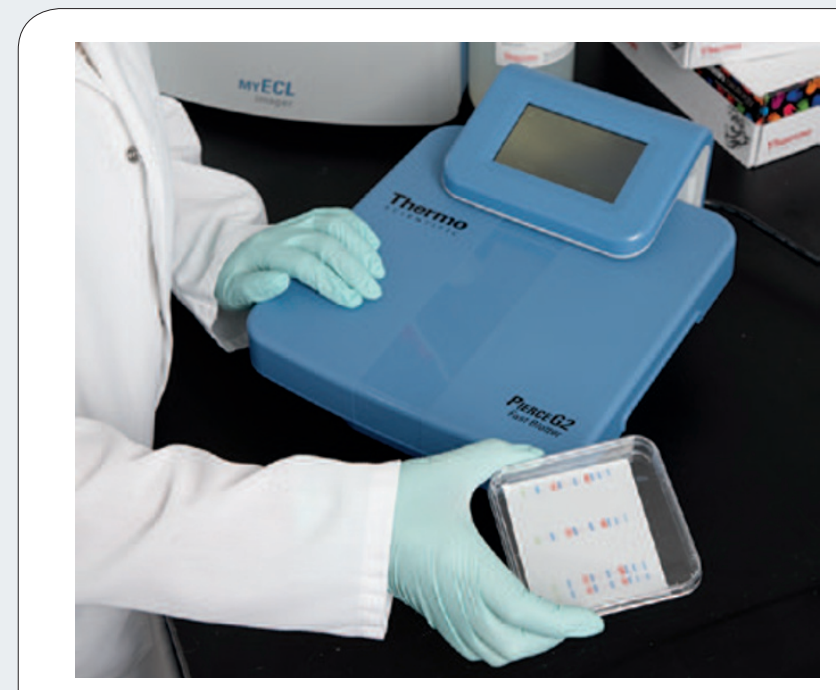

Figure 1 | The Thermo Scientific ${ }^{\mathrm{TM}}$ Pierce ${ }^{\mathrm{TM}} \mathrm{G} 2$ Fast Blotter can transfer proteins from gel to membrane in $10 \mathrm{~m}$.

Protein transfer using the Pierce ${ }^{\mathrm{TM}} \mathrm{G} 2$ Fast Blotter versus traditional tank method

HeLa lysate $(\sim 3.0 \mathrm{mg} / \mathrm{mL})$ prepared by nitrogen cavitation was serially diluted 1:2, prepared for SDS-PAGE and separated on gels according to suppliers' recommendations. The proteins were then transferred from gel to membrane using various techniques.

For electroblotting with the Pierce ${ }^{\mathrm{TM}} \mathrm{G} 2$ Fast Blotter, the gels, filter paper pre-wetted with Thermo Scientific ${ }^{\top M}$ Pierce $^{\text {TM }}$ 1-Step Transfer Buffer and membranes were assembled in the Pierce ${ }^{\mathrm{TM}} \mathrm{G} 2$ Fast Blotter Cassette as directed. The cassette was placed into the Pierce ${ }^{\mathrm{TM}} \mathrm{G} 2$ Fast Blotter Control Unit (Fig. 2), and proteins were transferred using the 'High MW' preprogrammed method for 1 minigel (1.3 amps constant, 25 volts limit, $10 \mathrm{~m}$ ).

For traditional overnight tank transfer, the gels, filter paper and membrane were equilibrated in cold Towbin buffer ${ }^{1}(25 \mathrm{mM}$ Tris, $192 \mathrm{mM}$ glycine, $20 \%$ methanol) for $15 \mathrm{~m}$. The transfer sandwich was assembled in a commercially available tank, and 30 volts constant was applied for $16 \mathrm{~h}$ at $4{ }^{\circ} \mathrm{C}$. 


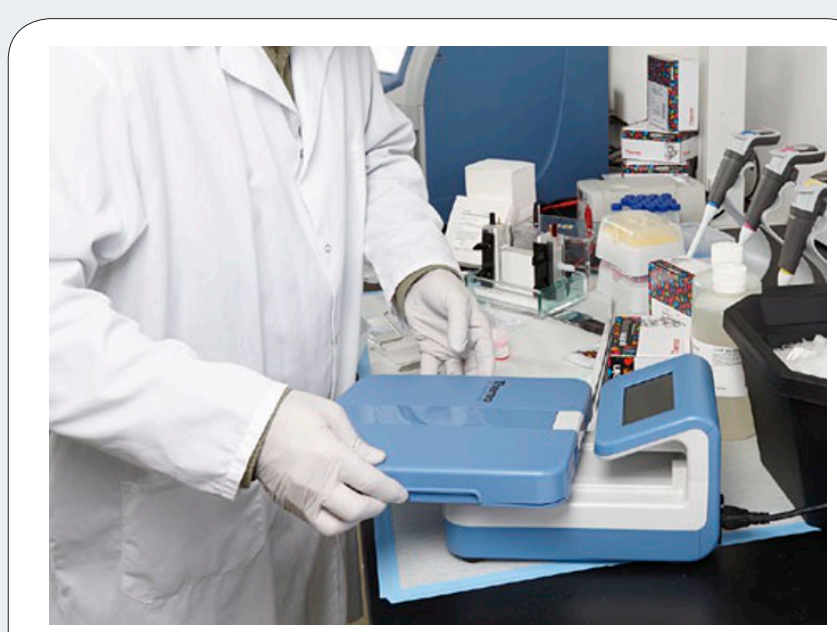

Figure $\mathbf{2}$ | The Pierce ${ }^{T M}$ G2 Blotter cassette, which contains the gel, blotting membrane and filter paper, inserts easily into the power supply. The transfer conditions are then selected using the touchscreen panel on the unit.

\section{Immunodetection}

Resulting membranes from the two transfer methods were cut into thirds. The top sections were probed with either Thermo Scientific ${ }^{\mathrm{TM}}$ anti-mTOR Antibody (Product \#PA1-518) or Thermo Scientific ${ }^{\text {TM }}$ antiEcm29 Antibody (Product \#PA3-035). The middle sections were probed with Thermo Scientific ${ }^{\text {TM }}$ anti-PLK1 Antibody (Product \#MA1-848), whereas the bottom parts were probed with Thermo Scientific ${ }^{\top M}$ antiCyclophilin B Antibody (Product \#PA1-027A). Antibodies were diluted in Thermo Scientific ${ }^{\text {TM }}$ Pierce Fast Blocking Buffer (Product \#37575). The membranes were then processed using Thermo Scientific ${ }^{\text {TM }}$ Pierce $^{\mathrm{TM}}$ Fast Western Blot Kits, SuperSignal ${ }^{\mathrm{TM}}$ West Dura Kits (Product \#35075 (Mouse) and \#35076 (Rabbit)). The resulting blots were then simultaneously imaged using the Thermo Scientific ${ }^{\text {TM }}$ MYECL ${ }^{\text {TM }}$ Imager (Product \#62236).

\section{Conclusion}

The Pierce ${ }^{\mathrm{TM}}$ G2 Fast Blotter in combination with Pierce ${ }^{\mathrm{TM}}$ 1-Step Transfer Buffer provides highly efficient transfer of low-, mediumand high-molecular weight proteins from polyacrylamide gels to nitrocellulose or PVDF membranes in just $10 \mathrm{~m}$. The transfer efficiency is equivalent to or better than that for traditional Western blotting transfer methods (Fig. 3). Of particular interest are the efficient 10-m transfers of mTOR and Ecm29, high-molecular weight proteins of approximately 298 kDa and 205 kDa, respectively, by the Pierce ${ }^{\mathrm{TM}}$ G2 Fast Blotter. Generally, high-molecular weight proteins are hard to transfer even using traditional tank methods. We have found that proteins up to $300 \mathrm{kDa}$ transfer well in $10 \mathrm{~m}$ using the Pierce ${ }^{\mathrm{TM}} \mathrm{G} 2$ Fast Blotter and the Pierce ${ }^{\mathrm{TM}}$ 1-Step Transfer Buffer (data not shown).

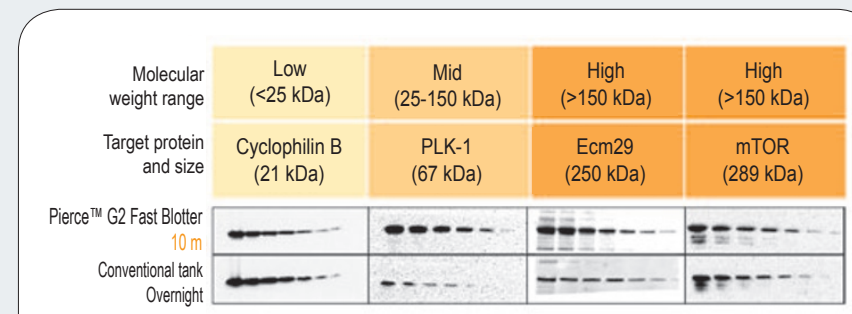

Figure $\mathbf{3}$ | Western blot comparison of low-, medium- and high-molecular weight proteins transferred to nitrocellulose membrane using various transfer techniques. The Thermo Scientific ${ }^{\mathrm{TM}}$ Pierce ${ }^{\mathrm{TM}} \mathrm{G} 2$ Fast Blotter rapidly transfers a wide range of molecular weight proteins to membrane with similar or better efficiency than traditional transfer methods, such as tank and semidry, as well as other rapid blotting systems. Experiment details can be found at http:// thermoscientific.com/g2blotter

1. Towbin, H., Staehelin, T. \& Gordon, J. Electrophoretic transfer of proteins from polyacrylamide gels to nitrocellulose sheets: procedure and some applications. Proc. Natl. Acad. Sci. USA 76, 4350-4354 (1979). 